\title{
A subdermal tagging technique for juvenile sturgeon using a new self-powered acoustic tag
}

\author{
Stephanie A. Liss ${ }^{*}$ (0), Huidong Li and Zhiqun Daniel Deng
}

\begin{abstract}
Background: A new technology for a self-powered acoustic tag (SPT) was developed for active tracking of juvenile fish, intended to avoid the typical battery life constraints associated with active telemetry technology. We performed a laboratory study to evaluate a subdermal tagging technique for the SPT and effects of the tag on survival, tag retention, and growth in juvenile white sturgeon (Acipenser transmontanus).

Results: Survival was associated with tag retention. White sturgeon implanted with the SPT $(n=30)$ had $93 \%$ survival and tag retention by day $28,67 \%$ by day 101 , and $38 \%$ by day 595 post-tagging. Sturgeon implanted with a passive integrated transponder (PIT) tag only (control group) had $96 \%$ survival and tag retention by day 28 , and through day 101 post-tagging. Fish in the PIT group were repurposed after day 101, so no comparisons with this group were made at day 595 post-tagging. Specific growth rate (SGR) for fork length was a median of $0.25 \%$ day $^{-1}$ by day 28 for the SPT group, which was significantly lower than the PIT group (median: $0.42 \%$ day $^{-1} ; n=27$ ). The SPT and PIT groups had similar SGR fork length by day 101 post-tagging $\left(0.22\right.$ and $0.25 \%$ day $^{-1}$, respectively). SGR weight was also lower for the SPT group compared to the PIT group on day 28 (1.39 and $2.11 \%$ day $^{-1}$, respectively), but the difference again dissipated by day 101 (0.79 and $0.88 \%$ day $^{-1}$, respectively).

Conclusion: The tagging technique and placement of the SPT allowed the tag to remain upright along the flank of the sturgeon to ensure maximum battery output of the SPT; however, retention rates of the SPT were not ideal. We provided suggestions to improve the tagging technique. Suggestions included tagging fish that are $>400 \mathrm{~mm} \mathrm{FL}$, moving the incision location to extend the cavity and create a pocket for the placement of the SPT, and performing a quantitative wound-healing evaluation. Future studies are therefore recommended to evaluate these suggestions.
\end{abstract}

Keywords: Acoustic telemetry, JSATS, Self-powered tag, Subdermal tagging technique, White sturgeon

\section{Background}

Acoustic telemetry is one of the primary tools used to understand the effects of anthropogenic activities (overfishing, changes in habitat due to hydroelectric projects or other dams, and pollution) on fish populations and changes in habitat use [1-3]. Acoustic telemetry allows researchers to monitor fish behavior, movement patterns, and survival $[1,4,5]$. However, the length of time fish can be monitored has been limited by the finite energy

*Correspondence: stephanie.liss@pnnl.gov

Pacific Northwest National Laboratory, Energy and Environment

Directorate, 902 Battelle Blvd, Richland, WA 99354, USA capacity of the battery life of the acoustic telemetry tag. For example, the battery life of smaller (i.e., $0.72 \mathrm{~g}$ in air) acoustic telemetry tags can last up to 365 days depending on the source level and ping rate interval (model: Juvenile Salmon Acoustic Telemetry System [JSATS] sturgeon transmitter) [6]. The battery life of other, larger telemetry tags (i.e., $24.0 \mathrm{~g}$ in air; model V16-4L; Innovasea Systems, Inc.; https://www.oceans-research.com/wpcontent/uploads/2016/09/v16-coded-1.pdf) can last up to 3650 days, also depending on the source level and ping rate interval. Long-lasting acoustic tags are beneficial for long-term monitoring. However, they are also typically larger in size to accommodate a bigger battery, in turn original author(s) and the source, provide a link to the Creative Commons licence, and indicate if changes were made. The images or other third party material in this article are included in the article's Creative Commons licence, unless indicated otherwise in a credit line to the material. If material is not included in the article's Creative Commons licence and your intended use is not permitted by statutory regulation or exceeds the permitted use, you will need to obtain permission directly from the copyright holder. To view a copy of this licence, visit http://creativecommons.org/licenses/by/4.0/. The Creative Commons Public Domain Dedication waiver (http://creativeco mmons.org/publicdomain/zero/1.0/) applies to the data made available in this article, unless otherwise stated in a credit line to the data. 
increasing the tag burden for fish (i.e., the weight of the tags relative to the weight of the fish). Tag burden is an important consideration in telemetry studies. For example, it can affect fish survival, growth, swimming behavior, ability to avoid predators or retain the tag, among others. If a tag burden is too large and has a negative effect on fish, it could bias the results of a telemetry study [7-10].

A current challenge in tagging studies is finding a tag size that balances battery life and fish size-at-tagging, to minimize a potential size bias. A size bias occurs when only the larger individuals in a population are tagged (to minimize tag burden), but they may not be representative of the entire size range of the population $[1,5,11]$. Studies monitoring long-term populations and habitat distributions have typically been restricted to tagging larger fish $[2,12,13]$. The ability to implant smaller fish could be beneficial for tracking long-lived species with severe population declines, such as sturgeon (Family Acipenseridae). Sturgeon have complex habitat requirements, late maturity $(10+$ years $[14,15])$, and slow rates of reproduction [16]. Their population declines are a result of life-history traits coupled with anthropogenic activities (overfishing, changes in habitat due to hydroelectric projects or other dams, and pollution) [15, 17]. In fact, 18 of the 25 species of sturgeon worldwide are listed as endangered or critically endangered [18]. Tag effects, population demographics, and habitat monitoring studies for adult sturgeon have been well documented; however, the ability to study juvenile sturgeon is important for monitoring early life behavior and understanding habitat preferences $[10,13,19,20]$. Ideally, implanting juvenile sturgeon with a long-lasting tag would allow for a better understanding of shifts in habitat preferences as sturgeon mature and provide population monitoring through several age classes.

Recently, a new active acoustic telemetry tag called the self-powered acoustic transmitter ("SPT" hereinafter) was developed. The SPT aims to address the issue of finite battery life by replacing the battery with a piezoelectric-based self-powered unit that harvests the biomechanical energy of the host animal's motion [21]. The SPT also addresses the fish size-at-tagging concern, because it weighs $0.80 \mathrm{~g}$ in air. It is similar in mass to the model JSATS sturgeon transmitter $(0.72 \mathrm{~g})$ and is $96.7 \%$ lighter than the model V16-4L (24.0 g). When implanted into fish, the self-powered unit harvests energy from the fish's natural swimming motion [21], giving it a unique functionality. Before the SPT can be used in field studies, species-specific biological testing is required to understand how best to implant the SPT (i.e., evaluate the tagging technique) and understand the potential tag effects of the SPT on a given species. Different tagging techniques and tag sizes, shapes, and volumes can have varying effects on each species; thus, species-specific guidelines are recommended $[1,11]$. We chose white sturgeon (Acipenser transmontanus) as the candidate species for this study. White sturgeon populations have been negatively affected by habitat fragmentation caused by dams, and there is a lack of understanding about juvenile populations and habitat use [10, 17, 20, 22]. Additionally, sturgeon have a cartilaginous skeleton and rough leathery skin $[23,24]$ that makes them an ideal candidate to meet the biological characteristics that affect the unique application of the SPT.

Biological aspects that influence the functionality of the SPT (i.e., the amount of power that can be harvested by the SPT) include the implantation location in the fish body and the fish's physical activity level and movement characteristics (e.g., degree of the body bending) [25]. Based on benchtop testing [25], the tagging technique would need to ensure that the SPT remains upright and in a fixed position inside the fish for the piezoelectric material of the SPT to bend sufficiently; in turn, effectively harvesting the mechanical energy required to power the tag. The tag bending would be generated by the natural swimming motion of the fish. The cartilaginous skeleton and rough leathery skin of sturgeon would provide a stable framework for the SPT to remain upright, and the natural wave-like bending of the body during swimming $[26,27]$ would promote power production to maximize the SPT battery output. The tag would not perform well if placed inside the body cavity, unless anchored, because it would not maintain an upright and fixed position. The length of the SPT (65 mm [21]) could make it difficult to implant internally even if anchored to the body wall. A long incision would likely be required, which could affect wound healing and recovery from surgery. Subsequent concerns for wound healing could occur if sutures were used to anchor the tag, as sutures could cause inflammation, ulceration, or water mold [28]. Externally attaching the transmitter, although potentially beneficial for positioning the SPT, could present problems for the fish during wound healing as the technique would also require the use of sutures [28]. Additionally, an external application could have detrimental effects on growth or tissue damage, or could affect fish performance if affixed to the side of the fish to maintain the SPT in an upright position, even if the SPT was neutrally buoyant [29]. Given the morphological characteristics of sturgeon and biological requirements of the SPT, we chose to use a subdermal tagging technique.

The objectives of our laboratory study were to evaluate the effects of the SPT on survival, tag retention, and growth of white sturgeon using a subdermal tagging technique designed for the SPT. The overall goal was 
to assess if the subdermal technique and tag placement would ensure proper functionality of the SPT (i.e., maximize the energy harvesting capabilities [25]), while minimizing negative tag effects to the fish, with the potential of developing a tagging protocol for use of the SPT in field studies.

\section{Methods}

\section{Fish rearing}

Fish care and use for this study were approved by Pacific Northwest National Laboratory's (PNNL) Institutional Animal Care and Use Committee (Protocol No. 201701) following the 8th Edition Guide for the Care and Use of Laboratory Animals [30]. Hatchery cultured age-0 white sturgeon $(n=140)$ were acquired from the Idaho Power Company in February 2017 (mean \pm standard deviation [SD] fork length [FL]: 193.9 $\pm 16.8 \mathrm{~mm}$; weight: $51.8 \pm 13.9 \mathrm{~g})$. We reared sturgeon at PNNL in two $600 \mathrm{~L}$ circular tanks that were located next to each other. Tanks were supplied with flow-through Columbia River water that was UV-treated, sand-filtered, and delivered at 3-4 tank volume exchanges each hour. The water $\mathrm{pH}$ range was 7-8 and the total dissolved gas range was $100-105 \%$. Water temperatures were set to $13 \pm 0.4{ }^{\circ} \mathrm{C}($ mean $\pm \mathrm{SD})$ upon arrival, and gradually increased by $1-2{ }^{\circ} \mathrm{C}$ per day until $17 \pm 0.5{ }^{\circ} \mathrm{C}$ to encourage growth and swimming activity for powering the SPT during the study. Sturgeon were subjected to a photoperiod similar to natural conditions set for Richland, WA, USA, using timer controlled overhead fluorescent bulbs (10 h light:14 h dark in February and gradually increasing to $16 \mathrm{~h}$ light: $8 \mathrm{~h}$ dark for the study start in May). We fed sturgeon Bio Vita pellets (Bio-Oregon, Longview, WA) daily to satiation, except prior to tagging and evaluation days, when they were unfed for $24 \mathrm{~h}$. Study conditions were the same as the rearing conditions.

\section{Tagging}

We tagged 57 white sturgeon on 1 May 2017 in two groups: passive integrated transponder ("PIT group" hereinafter) and self-powered tag ("SPT group" hereinafter; Table 1). Sturgeon in the PIT group received only a PIT tag $(12.2 \mathrm{~mm}$ length $\times 2.1 \mathrm{~mm}$ diameter, $0.1 \mathrm{~g}$; Fig. 1A) for individual identification, and represented a control group. Fish in the SPT group were triple tagged. The three tags were: (1) a PIT tag (Fig. 1A); (2) a nonfunctioning model JSATS sturgeon transmitter acoustic tag ("AT" hereinafter), that was the same dimension and weight as a functioning tag $(24.2 \mathrm{~mm}$ length $\times 5.0 \mathrm{~mm}$ diameter, 0.7 g; Fig. 1B); and (3) a non-functioning SPT that was also the same dimension and weight as a functioning tag $(65 \mathrm{~mm}$ length $\times 5.3 \mathrm{~mm}$ wide $\times 3.0 \mathrm{~mm}$ at the thickest point [i.e., the circuit board], $0.80 \mathrm{~g} ; 0.44$ $\mathrm{cm}^{3}$ in volume [21]; Fig. 1D and E). The SPT was coated in a $25 \mu \mathrm{m}$-thick layer of Parylene-C, encapsulated in ClearFlex 95 urethane rubber, and coated in another $25 \mu \mathrm{m}$-thick layer of Parylene-C to ensure that the transmitter was waterproof and biocompatible [21]. Additionally, all edges were rounded and smoothed out, to minimize potential irritation to the fish. The combined weight of the three tags in the SPT group, used for tag burden calculations, was $1.6 \mathrm{~g}$. Fish in the SPT group were triple tagged because it would be representative of what may occur in initial field trials. Hatchery-released or wild caught sturgeon are often PIT-tagged, and in an initial field trial, the AT would provide supplementary data to the SPT until the battery life of the AT expired.

Table 1 Sample sizes (n), fork lengths (FL), weights (WT), tag burdens, and specific growth rates (SGR) of white sturgeon (means \pm standard deviations with ranges in parentheses)

\begin{tabular}{|c|c|c|c|c|c|c|}
\hline Group & $n$ & $\mathrm{FL}(\mathrm{mm})$ & Weight (g) & Tag burden (\%) & $\mathrm{SGR}_{\mathrm{FL}}\left(\% \mathrm{~d}^{-1}\right)$ & $\mathrm{SGR}_{\mathrm{WT}}\left(\% \mathrm{~d}^{-1}\right)$ \\
\hline \multicolumn{7}{|c|}{ Tagging day (day 0) } \\
\hline SPT & 30 & $378 \pm 28.8(310-435)$ & $315 \pm 69(166-467)$ & $0.53 \pm 0.13(0.34-0.96)$ & & \\
\hline PIT & 27 & $370 \pm 28.8(320-415)$ & $298 \pm 82(169-436)$ & $0.04 \pm 0.01(0.02-0.06)$ & & \\
\hline \multicolumn{7}{|c|}{28 days post-tagging } \\
\hline SPT & 28 & $405 \pm 33.4(320-455)$ & $470 \pm 123(214-726)$ & & $0.25 \pm 0.15(0.00-0.49)$ & $1.39 \pm 0.76(-0.17-2.69)$ \\
\hline PIT & 26 & $414 \pm 29.6(360-460)$ & $517 \pm 126(303-716)$ & & $0.41 \pm 0.15(0.00-0.82)$ & $2.02 \pm 0.61(-0.11-2.82)$ \\
\hline \multicolumn{7}{|c|}{101 days post-tagging } \\
\hline SPT & 20 & $474 \pm 39.4(385-530)$ & $721 \pm 171(365-1027)$ & & $0.21 \pm 0.05(0.11-0.30)$ & $0.79 \pm 0.19(0.36-1.12)$ \\
\hline PIT & 26 & $472 \pm 31.2(410-525)$ & $702 \pm 166(414-1023)$ & & $0.24 \pm 0.06(0.06-0.32)$ & $0.86 \pm 0.21(0.21-1.10)$ \\
\hline \multicolumn{7}{|c|}{595 days post-tagging } \\
\hline SPT & 11 & $541 \pm 61.2(450-635)$ & $1014.9 \pm 339.8(569.5-1643.2)$ & & $0.06 \pm 0.02(0.03-0.08)$ & $0.19 \pm 0.04(0.11-0.25)$ \\
\hline
\end{tabular}




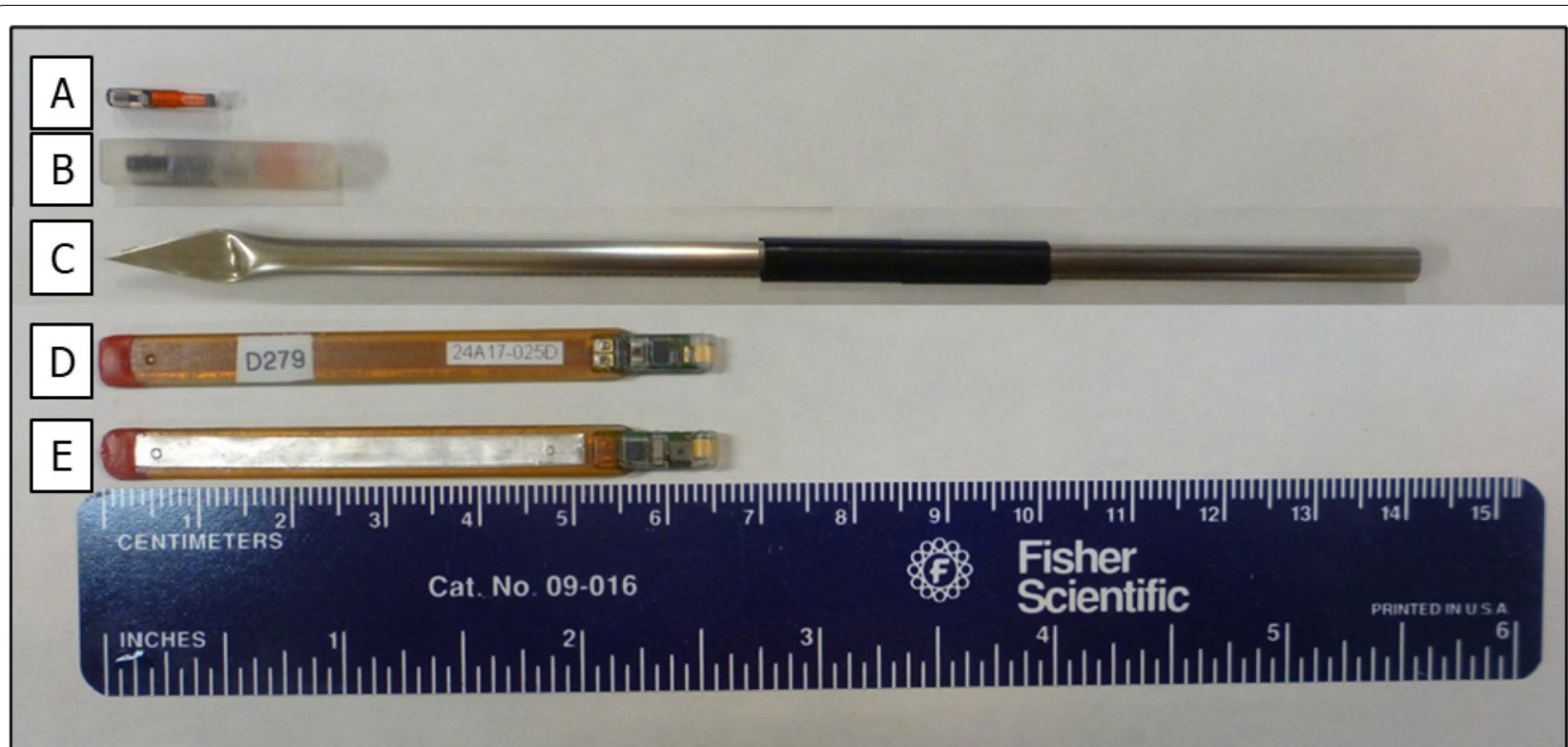

Fig. 1 Tags and tools used, depicting comparative dimensions of a A passive integrated transponder (PIT) tag; B non-functioning model JSATS sturgeon transmitter acoustic tag (AT); C 8.5-gauge needle used to make a cavity to hold the self-powered tag (SPT). The black electrical tape marked $70 \mathrm{~mm}$ from the needle tip, to ensure that the cavity created was longer than the SPT [65 mm]); and $\mathbf{D}$ and $\mathbf{E}$ the SPT, depicting the front and back of the tag, with the circuit board shown on the right side of the SPT

The supplementary data would allow for a comparison of how well the SPT performed.

Prior to each surgery, all tools and tags were disinfected with $70 \%$ ethanol for $15 \mathrm{~min}$ and rinsed in sterile water. The tagging process started by placing sturgeon in a knockdown dose of anesthesia (e.g., to stage 4 [31]), using $200 \mathrm{mg} / \mathrm{L}$ of MS-222 buffered with $200 \mathrm{mg} / \mathrm{L}$ of sodium bicarbonate. Time to knockdown in anesthesia and recovery in an aerated bucket of fresh water was less than 4 min each. During tagging, fish were placed on a pad and provided with fresh water through tubing. A maintenance dose of anesthesia ( $80 \mathrm{mg} / \mathrm{L}$ of MS-222 buffered with $80 \mathrm{mg} / \mathrm{L}$ of sodium bicarbonate) was provided if a fish woke up during tagging.

We injected all PIT tags (i.e., for the PIT and SPT groups) into the dorsal musculature on the right side of the dorsal fin using a needle and syringe. Total tagging time for the PIT group was less than $30 \mathrm{~s}$. The SPT group sturgeon were implanted first with the AT via a flank incision with a sterile \#11 blade. A 7-9 mm incision was centered between the 3rd and 4th ventral scutes anterior to the leading edge of the pelvic fin on the left side of the fish, without a suture closure [28]. Sutures or adhesives were not recommended for use to close the incision due to the potential for tissue necrosis, inflammation, ulceration, or water mold $[28,32]$. The PIT tag was injected next, into the dorsal musculature of the fish. Finally, the SPT was implanted. A vertical incision $8-10 \mathrm{~mm}$ long was made on the left side of the fish with a sterile \#11 blade. The incision was made between the dorsal and lateral rows of scutes above the second scute posterior of the pectoral fin (Figs. 2 and 3). A disinfected 8.5-gauge hypodermic tubing ( $0.156^{\prime \prime}$ outer diameter, $0.136^{\prime \prime}$ inner diameter) that was flattened and sharpened into a needle on one end (Fig. 2C) was used to create a horizontal cavity between the dermis and hypodermis tissue to hold the SPT in and upright and stationary position. The tubing needle was marked at $70 \mathrm{~mm}$ to indicate the distance the needle should be inserted, as the SPT was $65 \mathrm{~mm}$ long. The $70 \mathrm{~mm}$ cavity represented $\sim 16$ to $23 \%$ of the FL of the sturgeon. To create the cavity, we gently rotated the needle just underneath the epidermis to cut through the dermis and hypodermis tissue. The SPT was gently inserted in an upright position and pushed horizontally along the flank of the fish into the cavity, using forceps to aid the process if necessary. The thickest part of the SPT (i.e., the circuit board end) was inserted first, so the thinnest end was by the wound opening to minimize the potential for tag loss. The total tagging time to implant the three tags for fish in the SPT group was $2.8 \pm 0.1 \mathrm{~min}$ $($ mean $\pm S D)$.

\section{Monitoring}

Sturgeon were evaluated for FL, weight, and tag retention on 28 and 101 days post-tagging (Table 1). After 101 days post-tagging, the study ended for fish in the PIT 


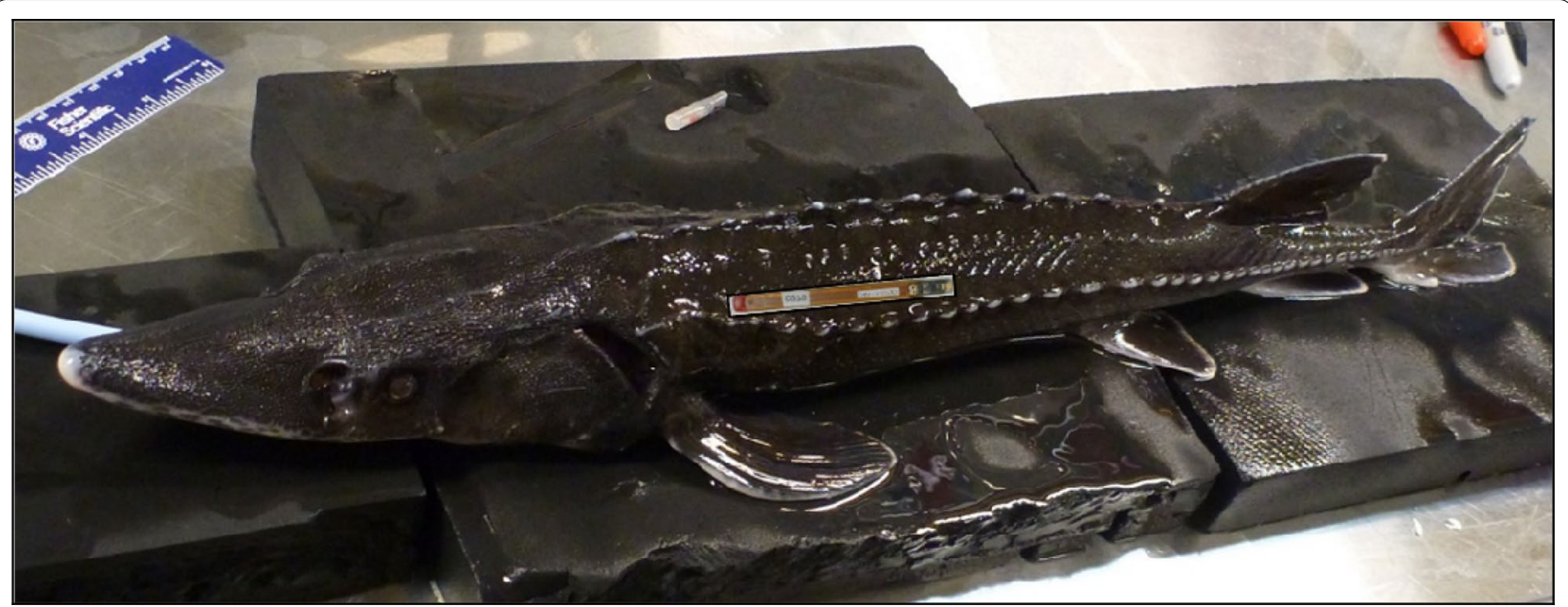

Fig. 2 Approximate location of the self-powered transmitter (SPT) to maximize energy output from the fish's natural swimming motion. The SPT pictured is overlain the sturgeon in an upright position for visual aid to where the SPT was implanted horizontally between the dermis and hypodermis tissue and is roughly to scale (65 $\mathrm{mm}$ in length)
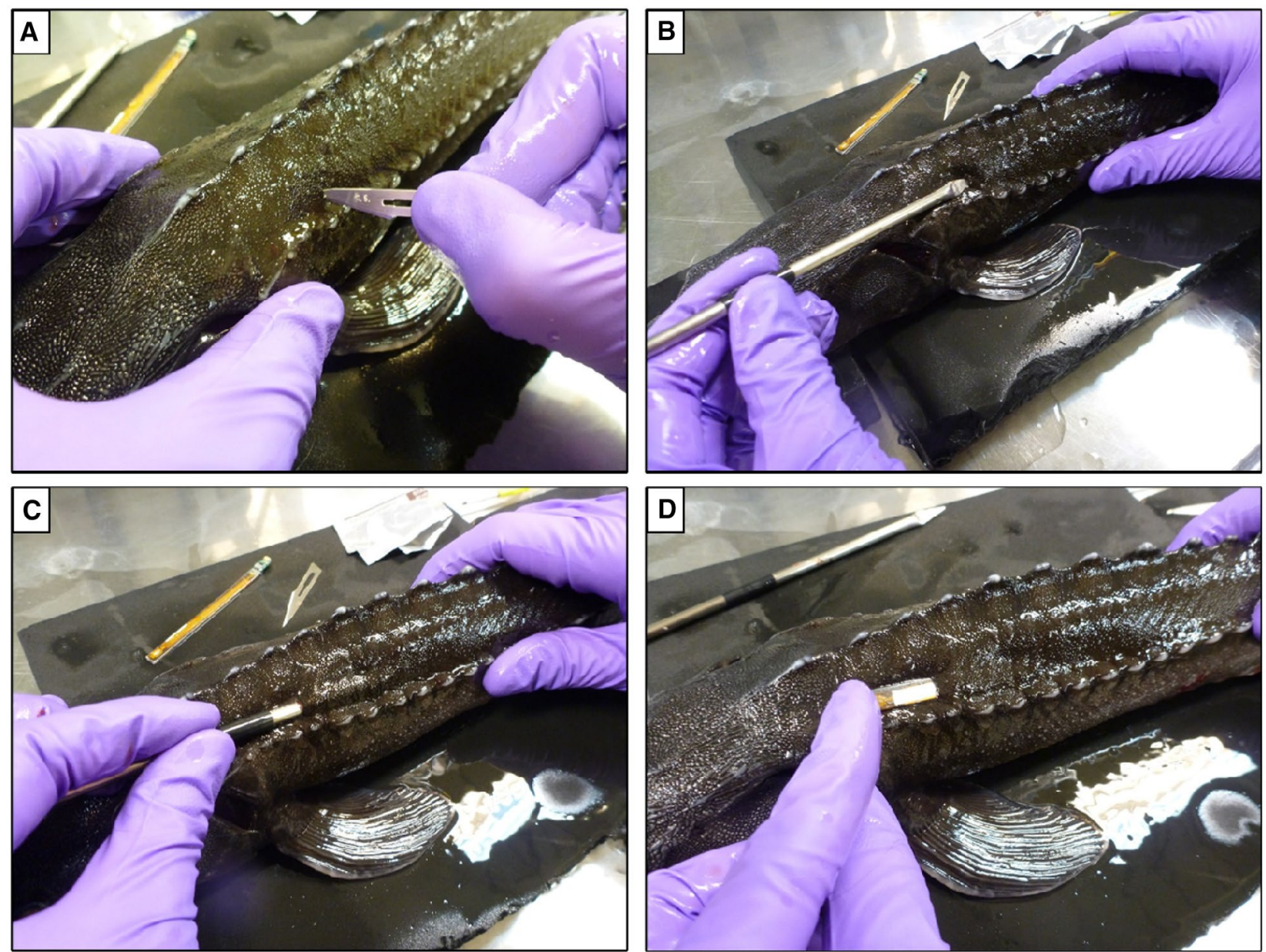

Fig. 3 Procedure for implanting the self-powered tag (SPT) in the flank location: A vertical incision with \#11 blade; B 8.5-gauge needle used to create the cavity; $\mathbf{C}$ creating the cavity for the SPT; $\mathbf{D}$ gently inserting the SPT into the cavity 
group as they were repurposed for another use. However, we monitored fish in the SPT group until 595 days post-tagging to continue evaluations of SPT retention (Table 1). Water temperature during the 28 day holding study was $17 \pm 0.5{ }^{\circ} \mathrm{C}$ (mean $\pm \mathrm{SD}$ ) to simulate summer river conditions. After the 28 day evaluation (May 2017), the water temperature was cooled by $1-2{ }^{\circ} \mathrm{C}$ per day to that of ambient river water $\left(\sim 13{ }^{\circ} \mathrm{C}\right)$ to follow natural river water temperature fluctuations for the remainder of the study, which was 101 days post-tagging for the PIT group (August 2017; temperature range: $\sim 13-21{ }^{\circ} \mathrm{C}$ ) and 595 days post-tagging for the SPT group (December 2018; temperature range: $\sim 5-21{ }^{\circ} \mathrm{C}$ ). After 595 days, fish in the SPT group were euthanized with an overdose of MS-222 and necropsied for evaluations of the effects of the SPT on the surrounding dermis and hypodermis tissue.

\section{Statistical analyses}

Data were evaluated for normality and homogeneity of variances using a Shapiro-Wilk test and a Levene's test, respectively. The SPT and PIT groups were compared to check for differences in FL or weight at the beginning of the study (day 0 ) using a $t$ test. Survival was defined by survival and tag retention, as a dead fish or a dropped tag in a field study would terminate active tracking [11]. Survival rates were quantified per group using proportions (i.e., the number of fish that survived and retained their PIT tag [PIT group] or all three tags in the SPT group, compared to the total number of fish in each group) and a Fisher's exact test [33]. We analyzed specific growth as a function of FL (in mm; $\mathrm{SGR}_{\mathrm{FL}}$ ) and weight (in grams; $\mathrm{SGR}_{\mathrm{WT}}$ ), represented by percent growth per day and using the formula

$$
\mathrm{SGR}=\left[\frac{\left(\ln \left[G_{\text {final }}\right]-\ln \left[G_{\text {initial }}\right]\right)}{\text { time }}\right] \times 100,
$$

where $S G R$ was represented by the percent growth gained per day $\left(\% \mathrm{~d}^{-1}\right), G$ was the growth (in $\mathrm{mm}[\mathrm{FL}]$ or $\mathrm{g}$ [weight]), and time was the study duration (in days) [34]. Growth data were assessed using a two-way repeated-measure analysis of variance (RMANOVA) to compare SGR across time (days 0, 28, and 101) and between groups. Non-normally distributed data were log-transformed and the RMANOVA was run separately on transformed and original data. If the RMANOVA tests on transformed and original data yielded the same results, we used the original (untransformed) data. Significant differences identified by the RMANOVA were followed up with a pairwise comparison $t$ test, performed with a Bonferroni correction to identify differences in $\mathrm{SGR}_{\mathrm{FL}}$ and $\mathrm{SGR}_{\mathrm{WT}}$ across time and between groups. The RMANOVA and assumptions of outliers, normality, and homogeneity of variances were evaluated using the package 'rstatix' in R [35]. Significance or Type I error $(\alpha)$ was defined at 0.05 for all statistical tests and analyses were performed in R [36].

\section{Results}

The FL and weight data for all study fish at the beginning of the study were normally distributed (Shapiro-Wilk: $W=0.98, P=0.32$ and $W=0.98, P=0.28$, respectively). Similarly, study fish FL and weight data had equal variances (Levene's test: $F=0.09, P=0.76$ and $F=1.81$, $P=0.18$, respectively). We used a Welch's $t$ test for unequal sample sizes to compare $\mathrm{FL}$ and weight data of the PIT and SPT groups. Neither the FL nor weight was different between groups $(t=1.05, P=0.30$ and $t=0.86$, $P=0.39$, respectively). Tag burdens (mean $\pm \mathrm{SD}$ ) for the SPT group were $0.53 \pm 0.13 \%$ and for the PIT group $0.04 \pm 0.01 \%$ (Table 1 ).

All fish in the SPT group $(n=30)$ retained their AT and PIT tags throughout the duration of the study. The wounds from the PIT injection and AT implantation were also healed (e.g., no inflammation, openness, ulceration, varicosities, or water mold [28]) by 28 days posttagging. Survival and SPT retention were $93 \%$ in the first 28 days post-tagging (Table 2). The two fish that dropped their SPTs were euthanized on the exam day, because the wounds at the SPT incision site were extensive. However, no other fish died or required euthanizing throughout the study. On day 28 , the SPT was visible in six fish (i.e.,

Table 2 Initial (day 0) fork lengths (FL), weights, and tag burdens of white sturgeon, and the number of days post-tagging a sturgeon dropped its self-powered tag (SPT group) or its PIT tag (PIT group)

\begin{tabular}{lllll}
\hline Group & FL (mm) & Weight $(\mathbf{g})$ & Tag Burden (\%) & $\begin{array}{l}\text { Dropped tag } \\
\text { (days post- } \\
\text { tagging) }\end{array}$ \\
\hline SPT & 370 & 341.2 & 0.47 & 5 \\
& 400 & 326.6 & 0.49 & 28 \\
& 340 & 234.5 & 0.68 & 29 \\
& 380 & 313.0 & 0.51 & 29 \\
& 340 & 198.8 & 0.80 & 29 \\
& 385 & 379.9 & 0.42 & 29 \\
& 395 & 380.5 & 0.42 & 30 \\
& 375 & 326.4 & 0.49 & 30 \\
& 360 & 254.0 & 0.63 & 31 \\
& 350 & 248.0 & 0.65 & 101 \\
PIT & $340-430$ & $235.3-399.3$ & $0.40-0.68$ & $102-595$ \\
\hline
\end{tabular}

The notation N/A indicates missing data. Fish that dropped their tags between days 101 and 595 post-tagging were combined $(n=9)$ as the individual days post-tagging were not recorded 
incision wound not healed and could either see the SPT inside the wound or the SPT was protruding from the incision). Of those six fish, three dropped their SPTs by day 31, along with an additional three fish that did not have visible SPTs (Table 2). The SPT incision sites on the other fish were closed and appeared to be healed. No fish dropped their SPT between days 31 and 101 (Table 2), although an SPT in one fish was coming through the epidermis on day 101. In this instance, the SPT was removed and considered a dropped tag (Table 2). Therefore, by day 101 survival and retention was $67 \%(n=20$ of 30$)$, and the wounds at the AT and SPT incision sites again appeared to be healed and healthy. Between day 101 and 595, one fish jumped out of the tank and died; therefore, it was excluded from the 595-day analysis. By day 595 post-tagging, $38 \%$ of sturgeon survived and retained their SPTs ( $n=11$ of 29; Table 2). In seven of the surviving fish (i.e., retaining the SPT), there was a fluid in the cavity where the SPT had been, and the SPT was bent in five fish. None of the fish with SPTs had necrotic tissue. Two fish that dropped their SPTs had long horizontal scars along the flank.

Sturgeon in the control (PIT group) had $100 \%$ survival and $96 \%$ ( $n=26$ of 27) PIT tag retention by day 28 (Table 2). The one dropped PIT tag was not recovered; therefore, the day it was dropped could not be determined. For the remainder of the study (through 101 days post-tagging), all other fish in the PIT group survived and retained their tags, maintaining the $96 \%$ survival and retention.

A Fisher's test was unable to detect a significant difference in survival and tag retention between the SPT and PIT groups at day $28(P=1.00)$. However, by 101 days post-tagging, survival between the two groups was significantly different $(P=0.006)$. No comparisons of survival for the PIT and SPT groups were made at 595 days posttagging, as only the SPT group was evaluated.

Fork length and weight SGR data did not have any extreme outliers and variances were not different. However, the data were not normally distributed for the PIT group at day 101 for $\mathrm{SGR}_{\mathrm{FL}}$ and at day 28 for $\mathrm{SGR}_{\mathrm{WT}}$. The RMANOVA from the log-transformed and original (untransformed) data resulted in the same conclusions for $\mathrm{SGR}_{\mathrm{FL}}$ and $\mathrm{SGR}_{\mathrm{WT}}$; therefore, we used the original data for both variables. Results indicated a significant effect on group and time for $\mathrm{SGR}_{\mathrm{FL}}(F=8.99, P<0.0001$ and $F=36.81, P<0.0001$, respectively). Follow-up pairwise comparison tests identified a difference in $\mathrm{SGR}_{\mathrm{FL}}$ on day $28(P<0.001)$ with a reduced growth in length for the SPT group compared to the PIT group (Fig. 4A). However, differences in $\mathrm{SGR}_{\mathrm{FL}}$ dissipated by 101 days posttagging $(P=0.07)$. Both groups experienced a decrease in growth for $\mathrm{SGR}_{\mathrm{FL}}$ from day 28 to day 101 post-tagging

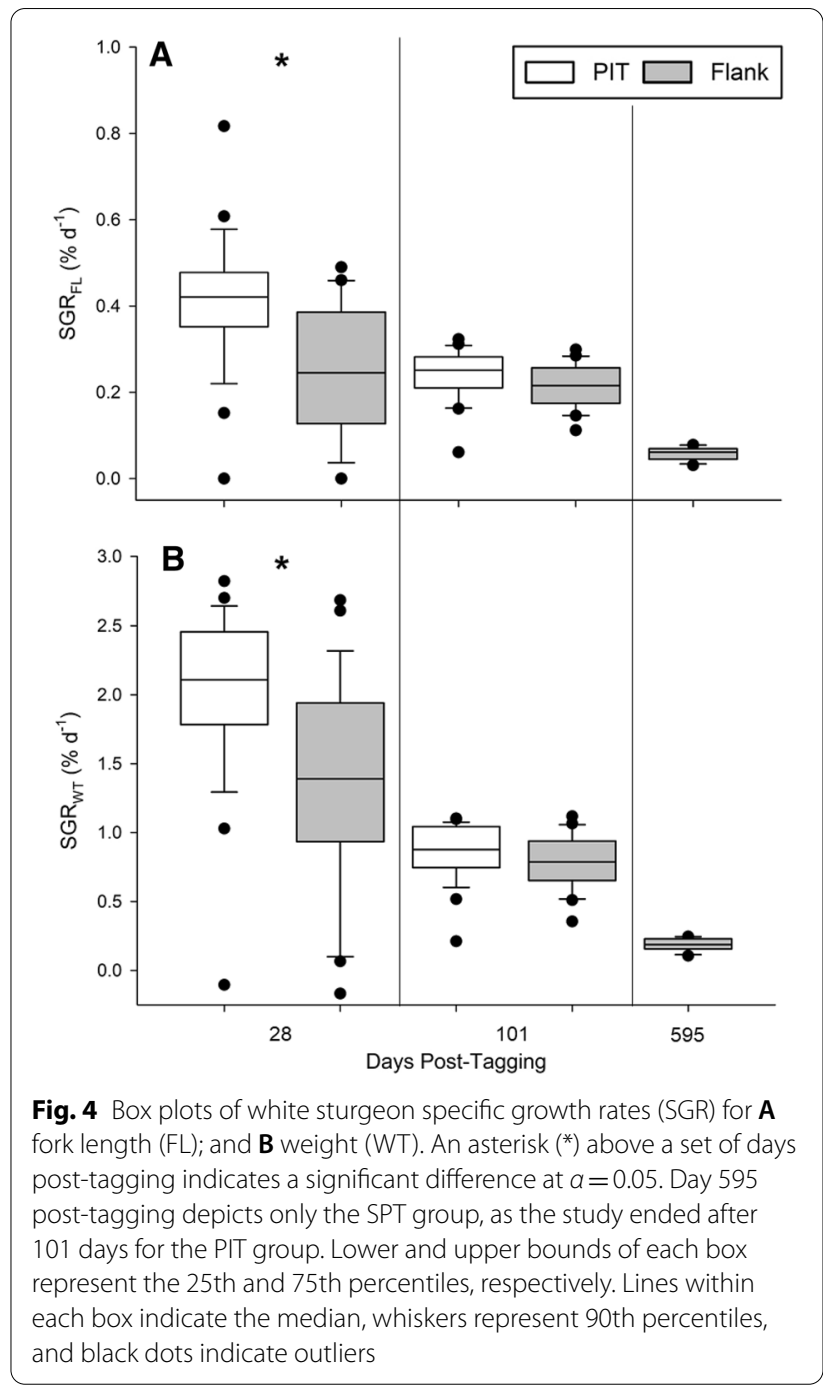

(Fig. 4A). Similarly, for $\mathrm{SGR}_{\mathrm{WT}}$, the RMANOVA identified a significant effect on group and time $(F=6.89$, $P<0.0001$ and $F=115.49, P=<0.0001$, respectively). Follow-up pairwise comparison tests identified a difference on day $28(P=0.002)$, indicating that SPT fish had a reduced weight gain compared to PIT fish (Fig. 4B). Differences in $\mathrm{SGR}_{\mathrm{WT}}$ also dissipated by 101 days post-tagging $(P=0.22)$. The SPT and PIT groups also experienced a decrease in weight for $\mathrm{SGR}_{\mathrm{WT}}$ from day 28 to day 101 post-tagging (Fig. 4B).

\section{Discussion}

The overall goal of this study was to evaluate a subdermal tagging technique designed for the SPT. The placement of the SPT needed to remain in an upright and fixed position that allowed for adequate tag bending, while minimizing negative effects on survival, tag retention, and growth to sturgeon. The tag placement and 
natural swimming motion of sturgeon would maximize the potential energy harvesting capabilities of the SPT, based on benchtop testing [25]. Even though 38\% of fish retained their SPT after 595 days, results of the tag placement were successful in the remaining fish. The SPT maintained an upright alignment along the flank, inside the dermis and hypodermis tissue for stability. However, some of these SPTs were bent and it is possible the bend would have broken the self-powering capability had the SPTs been functional, depending on the angle of the bend [25]. Sturgeon were located in a $600 \mathrm{~L}$ circular tank during the study, and may have turned and curved their bodies at an angle that caused the SPT to bend. The body curvature could have been indicative of a tank effect, although future studies should be performed to evaluate SPT effects on sturgeon swimming and natural locomotion to better understand this postulation.

Another potential cause of tag bending may have occurred when handling the fish during the examinations. Tag bending may have happened when fish were netted from the tank, or once they were put into the anesthesia and prior to being fully anesthetized. Despite the SPTs that bent, the location was a good choice for the potential to maximize the self-powered battery output. Future studies should use the flank location again, with modifications to the tagging technique, potentially the tank size or shape (i.e., $>600 \mathrm{~L}$ or not circular), or increase the size of the net or container used to anesthetize the fish to minimize bending prior to being fully anesthetized.

Regarding negative tag effects on the sturgeon, there were noticeable side effects for survival and tag retention. Tag retention of $67 \%$ (101 days) and 38\% (595 days) is not ideal for any telemetry tag, nor for a tag that is unrestricted by battery life. The cumulative tag burden of the three tags was $<1.0 \%$ and did not raise a concern for affecting fish survival or behavior [7, 9, 10]. Instead, the unique requirements of the technique may have contributed to the poor SPT retention. Although we chose to triple-tag sturgeon in the SPT group in this study (representative of what may occur in initial field trials), the PIT injection and surgical implantation of the AT were minimally invasive $[17,28]$. Wounds from the PIT injection and AT incision were healed by 28 days post-tagging and the SPT group had 100\% retention of these two tag types. Thus, it is unlikely the PIT and AT tags negatively affected SPT retention or survival.

The SPT tagging technique was invasive and created a deep internal wound $[37,38]$. Even though the external incision site was small $(8-10 \mathrm{~mm})$, the internal wound of the cavity was relatively large compared to the size of the fish, which may have increased the amount of time required for wound healing [37], in turn affecting SPT retention. The cavity required for the SPT created a $70 \mathrm{~mm}$ wound in the dermis and hypodermis tissue $(\sim 16$ to $23 \%$ of the FL of the sturgeon). For smaller $(<400 \mathrm{~mm}$ $\mathrm{FL}$ ) fish in this study, the length of the SPT was almost the same length as the side of the fish. During tagging, we also noticed that the larger fish had thicker dermis and hypodermis tissue on the flank than smaller fish. As a result, creating the cavity in smaller fish was more difficult and some of the SPTs did not slide into the cavity as easily. In our study, only eight fish in the SPT group were $>400 \mathrm{~mm} \mathrm{FL}$ (max: $435 \mathrm{~mm} \mathrm{FL)}$ ). Of those, four fish survived and retained their SPT through 595 days posttagging. Although limited in sample size, the results may indicate that sturgeon $>400 \mathrm{~mm}$ FL could recover from the tagging technique and retain their SPT better than smaller sturgeon. Future laboratory studies should try this technique with a larger sample size of sturgeon $>400 \mathrm{~mm}$ FL to evaluate if there is size effect.

The wound-healing process is well documented [3840]. For fish, the process includes re-epithelialization, inflammation, and reparation (formulation of granulation tissue and tissue remodeling/scarring) [37]. In our study, the SPT remained in the dermis and hypodermis tissue and could be described as a contusion wound-i.e., tissue loss and separation of tissue layers caused by severe laceration [38]. At the end of the study, we observed a fluid in the cavity of the majority $(63.6 \%)$ of the sturgeon, potentially indicative that the dermis and hypodermis tissue could not fully reconstruct or go through the reparation process. The presence of the SPT likely blocked the tissue from apposition, a response that may affect wound healing in fish [37]. Wound healing may have also slowed during times when river water temperatures were cooler $[37,41]$, prolonging the wound-healing process. With this technique, it is possible the internal wound could not heal completely, although the external incision appeared to heal and close the wound opening. A better understanding of contusion wound healing in fish is needed, and future studies should quantitatively evaluate the wound-healing process $[28,42,43]$.

Dropped SPTs may have been pushed through the incision site if the wound did not close or heal. Although we observed the SPT incision site to be closed and healed for the majority of sturgeon that survived to day 28 , the underlying tissue by the incision site may not have completely healed. Because the tissue may have been damaged or inflamed, the SPT could have been expelled through the incision site. We noticed this on day 101, as one fish had an open incision site with the SPT protruding. For smaller sturgeon where the length of the SPT was almost the length of the side of the body, they may have been able to push the SPT out inadvertently as a result of their natural swimming and bending motion. Another 
possible location where SPT may have been expelled was through the epidermis. For example, two fish were observed to have a long horizontal scar, similar in outline to the shape of the SPT. The SPT may have been recognized as a foreign material in the body, became engulfed by cells trying to clear the foreign material, and may have been expelled from the body of the sturgeon, i.e., a form of the phagocytic process [37, 44, 45]. This may be an unavoidable constraint for the SPT in the future, regardless of the tagging technique.

To address SPT retention, another recommendation to the tagging technique is to move the incision to potentially improve the retention of the SPT in the cavity. The incision location would move to between the 4th and 5th ventral scutes anterior to the leading edge of the pelvic fin and the cavity would be created to extend on both sides of the incision. The short end of the cavity (pocket) would be on the left (anterior) side of the incision and 3-4 $\mathrm{mm}$ in length; or the approximate length from the 4th to the 3rd scute moving anteriorly. The long end of the cavity would be the same as described in our methods $(70 \mathrm{~mm}$ in length, moving posteriorly). The creation of the pocket would provide a space for the surgeon to tuck the end of the SPT, so the end of the SPT would no longer be located at the incision site opening. Both ends of the SPT would be covered by tissue and skin, potentially minimizing the ability for the SPT to be pushed out through the incision. Moving the incision location and creating a pocket would allow the SPT to remain in the same location along the flank to maximize energy output of the SPT. In this study, we noticed that the end of the SPT was still visible at the incision site immediately after implantation for some fish. A cavity on both sides of the incision may also allow the SPT to slide more smoothly into place, while ensuring the end of the SPT is not visible at the incision site. Although the addition of the pocket may create a longer cavity, in turn creating a longer internal wound, it may also aid in wound healing at the incision site. If the end of the SPT is not at the incision site, it may reduce irritation and aid in external wound healing and incision closure. A longer cavity with a pocket on the left side of the incision would be preferred to a suture closure. Suture closures are not recommended for juvenile white sturgeon, because the suture material can cause inflammation, ulceration, or water mold infections $[17,28]$.

There were also short-term side effects for growth through the first 28 days post-tagging, although these effects were no longer apparent by 101 days. Sturgeon in the PIT group had significantly better $\mathrm{SGR}_{\mathrm{FL}}$ and $\mathrm{SGR}_{\mathrm{WT}}$ in the short term compared to the SPT group. The SPT group sturgeon were likely allocating energy toward wound healing and recovery from the stress of surgical tag implantation in the first 28 days, as opposed to growth [46]. The decrease in growth for FL and weight in the PIT and SPT groups from day 28 to day 101 post-tagging is logical, as sturgeon follow a growth curve [34, 47, 48]. Sturgeon experience increased growth during early life stages, with growth leveling off as they mature [34, 47, 48]. The decrease in growth was also evident by day 595 for the SPT fish, although the more pronounced decrease may have also been a result of the water temperature. After 28 days post-tagging, the water temperature was no longer held constant and was set to ambient river water temperatures. The 595 day exam date was in December when water temperatures were cooler $\left(\sim 5{ }^{\circ} \mathrm{C}\right)$ than at day 28 (May; $\sim 13{ }^{\circ} \mathrm{C}$ ) and day 101 (August; $\sim 2{ }^{\circ} \mathrm{C}$ ). Water temperature can affect fish feeding and growth, which is reduced when water temperatures are cooler $[46,49]$.

This study started with the potential for developing a tagging protocol for use of the SPT in field studies. Although the technology and tagging technique have not been demonstrated in the field yet [25] (and the current study), our results nonetheless provide beneficial information that future studies can use to continue to refine a technique that ensures the survival and health of sturgeon are minimally affected. Researchers are continuing to develop the SPT technology [25], using the biological information provided herein. Future studies on the tagging technique are important, so when the technology is ready, the technique will also be ready for researchers to use. The novel technology of the SPT combined with the ability to implant juvenile sturgeon has the potential for long-term data collection. This would lead to a better understanding of sturgeon movement patterns and habitat preferences beginning at the juvenile life stage and provide critical information that could help fill current knowledge gaps.

\begin{abstract}
Acknowledgements
We thank several staff at Idaho Power Company for their fish husbandry and discussions during the study: Phil Bates, Jake Hughes, and Ken Lepla. We also thank staff from PNNL for their fish husbandry, assistance with data collection, and manuscript reviews: Jill Janak, Tim Linley, Brett Pflugrath, and David Geist. We also thank Idaho Power Company for providing white sturgeon.
\end{abstract}

\section{Authors' contributions}

SAL made substantial contributions of the design of the research, the acquisition, analysis, and interpretation of the data, and drafted the manuscript. $\mathrm{HL}$ and ZDD made substantial contributions to the creation of the new technology used in the research and substantively revised the manuscript. All authors read and approved the final manuscript.

\section{Funding}

This study was funded by the U.S. Department of Energy Water Power Technologies Office and was conducted at PNNL, which is operated by Battelle for the Department of Energy under Contract No. DE-AC05-76RL01830.

\section{Availability of data and materials}

The datasets used and/or analyzed during the current study are available from the corresponding author on reasonable request. 


\section{Declarations}

Ethics approval and consent to participate

Fish care and use for this study were approved by PNNL's Institutional Animal Care and Use Committee (Protocol No. 2017-01).

\section{Consent for publication}

Not applicable.

\section{Competing interests}

The authors declare that they have no competing interests.

Received: 14 September 2021 Accepted: 7 February 2022

Published online: 25 February 2022

\section{References}

1. Cooke SJ, Woodley CM, Eppard MB, Brown RS, Nielsen JL. Advancing the surgical implantation of electronic tags in fish: a gap analysis and research agenda based on a review of trends in intracoelomic tagging effects studies. Rev Fish Biol Fish. 2011;21:127-51.

2. Lindley ST, Erickson DL, Moser ML, Williams G, Langness OP, McCovey BW, et al. Electronic tagging of green sturgeon reveals population structure and movement among estuaries. Trans Am Fish Soc. 2011;140:108-22.

3. Trested DG, Ware K, Bakal R, Isely JJ. Microhabitat use and seasonal movements of hatchery-reared and wild shortnose sturgeon in the Savannah river, South Carolina-Georgia. J Appl Ichthyol. 2011;27:454-61.

4. Deng ZD, Carlson TJ, Li H, Xiao J, Myjak MJ, Lu J, et al. An injectable acoustic transmitter for juvenile salmon. Sci Rep. 2015;5:8111

5. Peven C, Giorgi A, Skalski J, Langeslay M, Grassell A, Smith S, et al. Guidelines and recommended protocols for conducting, analyzing, and reporting juvenile salmonid survival studies in the Columbia River Basin. Wenatchee; 2005

6. Lu J, Deng ZD, Li H, Myjak MJ, Martinez JJ, Xiao J, et al. A small long-life acoustic transmitter for studying the behavior of aquatic animals. Rev Sci Instrum. 2016:87(11):114902

7. Brown RS, Cooke SJ, Anderson WG, McKinley RS. Evidence to challenge the "2\% rule" for biotelemetry. N Am J Fish Manag Wiley. 1999;19:867-71.

8. Brown RS, Harnish RA, Carter KM, Boyd JW, Deters KA, Eppard MB. An evaluation of the maximum tag burden for implantation of acoustic transmitters in juvenile chinook salmon. N Am J Fish Manag. 2010:30:499-505

9. Miller EA, Froehlich HE, Cocherell DE, Thomas MJ, Cech JJ, Klimley AP, et al. Effects of acoustic tagging on juvenile green sturgeon incision healing, swimming performance, and growth. Environ Biol Fishes. 2014;97:647-58.

10. McCabe MM, Chiotti JA, Boase JC, Fisk AT, Pitcher TE. Assessing acoustic tagging effects on survival, growth, and swimming ability of juvenile lake sturgeon. N Am J Fish Manag. 2019;39:574-81.

11. Liss SA, Znotinas KR, Blackburn SE, Fischer ES, Hughes JS, Harnish RA, et al. From 95 to 59 millimetres: a new active acoustic tag size guideline for salmon. Can J Fish Aquat Sci. 2021;15:1-15.

12. Colborne SF, Hondorp DW, Holbrook CM, Lowe MR, Boase JC, Chiotti JA, et al. Sequence analysis and acoustic tracking of individual lake sturgeon identify multiple patterns of river-lake habitat use. Ecosphere. 2019. https://doi.org/10.1002/ecs2.2983

13. Sweka JA, Mohler J, Millard MJ, Kehler T, Kahnle A, Hattala K, et al. Juvenile atlantic sturgeon habitat use in Newburgh and Haverstraw bays of the Hudson river: implications for population monitoring. N Am J Fish Manag. 2007;27:1058-67

14. Hochleithner M, Gessner J. The sturgeons and paddlefishes of the world: biology and aquaculture. 106th ed. Kitzbuhel, Austria: Aquatech Publications; 2001.

15. Katopodis C, Cai L, Johnson D. Sturgeon survival: the role of swimming performance and fish passage research. Fish Res. 2019;212:162-71.

16. He F, Zarfl C, Bremerich V, David JNW, Hogan Z, Kalinkat G, et al. The global decline of freshwater megafauna. Glob Chang Biol. 2019:25:3883-92.

17. Ashton NK, Liss SA, Walker RW, Brown RS, Klassen C, Backhouse S, et al. How low can you go? determining a size threshold for implantation of a new acoustic transmitter in age-0 white sturgeon. Northwest Sci. 2017;91(1):69-80.

18. The IUCN red list of threatened species. Int Union Conserv Nat. 2018 https://www.iucnredlist.org/. Accessed 1 Sept 2021.

19. Carrera-García E, Kordek J, Gesset C, Jacobs L, Acolas ML. Tracking juvenile sturgeon in the wild: miniature tag effects assessment in a laboratory study on Siberian sturgeon (Acipenser baerii). Fish Res. 2017; 186:337-44

20. Peterson DL, Vecsei $P$, Jennings $C A$. Ecology and biology of the lake sturgeon: a synthesis of current knowledge of a threatened North American Acipenseridae. Rev Fish Biol Fish. 2007;17:59-76.

21. Li H, Tian C, Lu J, Myjak MJ, Martinez JJ, Brown RS, et al. An energy harvesting underwater acoustic transmitter for aquatic animals. Sci Rep. 2016:6:1-9.

22. Bates P, Chandler J, Lepla K, Steinhorst K. Using mark-recapture data in an individual-based model to evaluate length-at-age differences between two snake river white sturgeon (Acipenser transmontanus Richardson, 1836) populations in Idaho, USA. J Appl Ichthyol. 2014;30:1319-27

23. Holliman FM, Reynolds JB. Electroshock-induced injury in juvenile white sturgeon. N Am J Fish Manag. 2002;22:494-9.

24. Gilmore CW, Cochran DM. Cold-blooded vertebrates part 1 fishes, vol. Eig. Washington, D.C.: Smithsonian Scientific Series; 1930.

25. Li H, Lu J, Myjak MJ, Liss SA, Brown RS, Tian C, et al. An implantable biomechanical energy harvester for animal monitoring devices. Nano Energy. In Submiss.

26. Long JH. Morphology, mechanics, and locomotion: the relation between the notochord and swimming motions in sturgeon. Environ Biol Fishes. 1995:44:199-211.

27. Webb PW, Kostecki PT, Don SE. The effect of size and swimming speed on locomotor kinematics of rainbow trout. J Exp Biol. 1984;109:77-95.

28. Liss SA, Ashton NK, Brown RS, Walker RW, Bates P, Klassen C, et al. Evaluation of four surgical implantation techniques for age-0 white sturgeon (Acipenser transmontanus Richardson, 1836) with a new acoustic transmitter. J Appl Ichthyol. 2017;34:382-9.

29. Janak JM, Brown RS, Colotelo AH, Pflugrath BD, Stephenson JR, Deng ZD, et al. The effects of neutrally buoyant, externally attached transmitters on swimming performance and predator avoidance of juvenile chinook salmon. Trans Am Fish Soc. 2012;141:1424-32.

30. NRC. Guide for the care and use of laboratory animals, guid care use lab anim. 8th ed. Washington, DC: The National Academies Press; 2011.

31. Summerfelt RC, Smith LS. Anesthesia, surgery, and related techniques. In: Schreck CB, Moyle PB, editors. Methods fish Biol. Bethesda: Maryland American Fisheries Society; 1990. p. 213-72.

32. Wagner GN, Cooke SJ, Brown RS, Deters KA. Surgical implantation techniques for electronic tags in fish. Rev Fish Biol Fish. 2011;21:71-81.

33. Fisher RA. Statistical methods for research workers. In: Kotz S, Johnson NL, editors. Break Stat. New York, NY: Springer; 1992.

34. Ricker WE. Computation and interpretation of biological statistics of fish populations. Ottawa: Canada; 1975.

35. Kassambara A. 2021. rstatix: Pipe-friendly framework for basic statistical tests. R package version 0.7.0. https://CRAN.R-project.org/package=rstat

36. R Core Team. R: A language and environment for statistical computing. $\mathrm{R}$ Foundation for Statistical Computing. Vienna; 2018.

37. Sveen L, Karlsen C, Ytteborg E. Mechanical induced wounds in fish-a review on models and healing mechanisms. Rev Aquac. 2020;12:2446-65.

38. Strodtbeck F. Physiology of wound healing. Newborn Infant Nurs Rev. 2001;1:43-52.

39. Gonzalez ACDO, Andrade ZDA, Costa TF, Medrado ARAP. Wound healing - a literature review. An Bras Dermatol. 2016;91:614-20.

40. Velnar T, Bailey T, Smrkolj V. The wound healing process: an overview of the cellular and molecular mechanisms. J Int Med Res. 2009;37:1528-42.

41. Panther JL, Brown RS, Gaulke GL, Deters KA, Woodley CM, Brad EM. Influence of incision location on transmitter loss, healing, survival, growth, and suture retention of juvenile chinook salmon. Trans Am Fish Soc. 2011;140:1492-503.

42. Boone SS, Hernandez SM, Camus AC, Peterson DL, Jennings CA, Shelton $J$, et al. Evaluation of four suture materials for surgical incision closure in siberian sturgeon. Trans Am Fish Soc. 2013;142:649-59. 
43. Crossman JA, Hammell KL, Litvak MK. Experimental examination of surgical procedures for implanting sonic transmitters in juvenile shortnose sturgeon and Atlantic sturgeon. N Am J Fish Manag. 2013;33:549-56.

44. Åsbakk K, Dalmo RA. Atlantic salmon (Salmo salar L) epidermal Malpighian cells-motile cells clearing away latex beads in vitro. J Mar Biotechnol. 1998;6:30-4.

45. Åsbakk K. Elimination of foreign material by epidermal malpighian cells during wound healing in fish skin. J Fish Biol. 2001;58:953-66.

46. Schreck CB, Tort L, Farrell AP, Brauner CJ. Biology of stress in fish. Cambridge: Academic Press; 2016.

47. Paragamian VL, Beamesderfer RCP. Growth estimates from tagged white sturgeon suggest that ages from fin rays underestimate true age in the Kootenai river, USA and Canada. Trans Am Fish Soc. 2003;132:895-903.

48. Brennan JS, Cailliet GM. Comparative age-determination techniques for white sturgeon in California. Trans Am Fish Soc. 1989;118:296-310.

49. Kappenman KM, Fraser WC, Toner M, Dean J, Webb MAH. Effect of temperature on growth, condition, and survival of juvenile shovelnose sturgeon. Trans Am Fish Soc. 2009;138:927-37.

\section{Publisher's Note}

Springer Nature remains neutral with regard to jurisdictional claims in published maps and institutional affiliations.

- fast, convenient online submission

- thorough peer review by experienced researchers in your field

- rapid publication on acceptance

- support for research data, including large and complex data types

- gold Open Access which fosters wider collaboration and increased citations

- maximum visibility for your research: over $100 \mathrm{M}$ website views per year

At $\mathrm{BMC}$, research is always in progress.

Learn more biomedcentral.com/submissions 